\title{
Dynamical Differences in Respiratory Syncytial Virus
}

\author{
Ryan Heumann ${ }^{1} \cdot$ Carly Duncan ${ }^{2}$. Christopher C. Stobart ${ }^{2}$. \\ Scott Kaschner ${ }^{1}$ (D)
}

Received: 7 June 2021 / Accepted: 15 November 2021 / Published online: 30 November 2021 (c) The Author(s), under exclusive licence to Society for Mathematical Biology 2021

\begin{abstract}
Respiratory syncytial virus (RSV) is a leading viral cause of pediatric respiratory infections and early infant mortality. Despite extensive development efforts currently underway, there remain no vaccines available for the prevention of RSV. RSV is an enveloped, negative-strand RNA virus that utilizes two different proteins ( $G$ and F) to mediate attachment and entry into host cells. These $\mathrm{G}$ and $\mathrm{F}$ proteins are the primary determinants of viral strain-specific differences and elicit protective neutralizing antibodies during natural infection in humans. Earlier studies have demonstrated that these proteins play an additional role in regulating the stability of RSV particles in response to temperature and $\mathrm{pH}$. However, it remains unclear how much variability exists in the stability of RSV strains and what contribution changes in temperature and $\mathrm{pH}$ make to the clearance of virus during an active infection. In this study, we evaluated the impacts of changes in temperature and $\mathrm{pH}$ on the inactivation of four different chimeric recombinant RSV strains that differ exclusively in G and F protein expression. Using these data, we developed predictive mathematical models to examine the specific contributions and variations in susceptibility that exist between viral strains. Our data provide strain-specific clearance rates and temperature-pH landscapes that shed light on the optimal contributions of temperature and $\mathrm{pH}$ to viral clearance. These
\end{abstract}

This research was partially funded by a Holcomb Awards Committee (HAC) grant from Butler University and summer undergraduate research support through the Butler Summer Institute (BSI).

Scott Kaschner

skaschne@butler.edu

Ryan Heumann

rheumann@butler.edu

Carly Duncan

ceduncan@butler.edu

Christopher C. Stobart

cstobart@butler.edu

1 Department of Mathematics, Statistics, and Actuarial Science, Butler University, 4600 Sunset Ave, Indianapolis, IN 46208, USA

2 Department of Biological Sciences, Butler University, 4600 Sunset Ave, Indianapolis, IN 46208, USA 
provide new insight into how much variation exists in the clearance of a major respiratory pathogen and may offer new guidance on optimization of viral strains for development of live-attenuated vaccine preparations.

Keywords Respiratory syncytial virus $\cdot$ RSV $\cdot$ Mathematical model $\cdot$ Virus stability

\section{Introduction}

Human respiratory syncytial virus (RSV) is a major respiratory pathogen associated with both upper and lower respiratory disease in young infants, the elderly, and immunocompromised adults. RSV is the leading viral cause of acute lower respiratory illnesses (ALRI) in early childhood (under age 5) and a leading cause of early childhood mortality worldwide. In 2015, there were estimated 33 million cases of RSV-associated ALRI globally in this population that were associated with a hospitalization rate of approximately $10 \%$ (Shi et al. 2017). In the USA, it is estimated that 1 in 13 primary care office visits are due to RSV infections in children under 5 (Hall et al. 2009). Despite a high clinical burden both in the USA and globally, there remain no vaccines available and the only prophylaxis option (Palivizumab) for young infants to mitigate RSV disease is largely reserved for high-risk populations in the developed world due largely to its high expense (Simões et al. 2018).

RSV is an enveloped, negative-strand RNA virus that uses two different surface glycoproteins ( $\mathrm{G}$ and $\mathrm{F}$ ) to mediate attachment and entry into host cells, respectively (Collins and Melero 2011). Both RSV G and F are capable of eliciting protective neutralizing antibodies and remain the primary antigen targets of most vaccine design efforts (Collins and Melero 2011; Anderson et al. 1986). Efforts to develop a vaccine for RSV have been hindered due to a wide array of biological and technical challenges since the virus' discovery in the 1950s. Early attempts in the 1960s to develop an adjuvanted formalin-inactivated vaccine for RSV led to severe exacerbation of disease rather than protection upon subsequent natural exposure (Kim et al. 1969). This failure largely deterred vaccine development for many years and has directed current pediatric vaccine design efforts toward the development of a live-attenuated vaccine for RSV (Collins and Melero 2011). Live-attenuated vaccine candidates for RSV remain the only type of vaccines that have not primed for enhanced RSV disease in naïve populations (Wright et al. 2007; DeFord et al. 2019). However, during natural RSV infections, the virus utilizes a pair of nonstructural proteins (NS1 and NS2) to antagonize the host innate and adaptive immune responses (Munir et al. 2011; Thornhill and Verhoeven 2020; Meng et al. 2014). Consequently, natural RSV infections in infants are rarely fully protective with multiple infections by homologous strains being possible. Furthermore, RSV has a legacy of physical instability making efforts to develop physically stable vaccine candidates more difficult (Stobart et al. 2016). Soon after its discovery, early studies using the RSV Long strain showed that the virus was sensitive to both temperature and $\mathrm{pH}$ variations (Hambling 1964). More recently, we showed that susceptibility to inactivation by physical and chemical factors was variable among multiple strains (DeFord et al. 2019; Stobart et al. 2016; Rostad et al. 2018). However, it is unclear how differences in these viruses regulate viral stability 
and what contributions environmental factors such as temperature and $\mathrm{pH}$ make to viral clearance during active infections.

Mathematical models have been successfully used to describe the infection dynamics of several different prominent human viral pathogens including Ebola, HIV, and Influenza (Perelson et al. 1996; Nguyen et al. 2015; Baccam et al. 2006). Recently, mathematical models have also be generated for RSV that predict both in vitro and in vivo replication dynamics (González-Parra and Dobrovolny 2019, 2018). However, the recent discovery of appreciable differences in stability between RSV strains led us to hypothesize that both temperature and $\mathrm{pH}$ also play important strain-specific roles in viral clearance of RSV infection. In this study, we utilize a panel of four recombinant RSV strains (A2, A2-line19F, A2-91/09GF, A2-TX11-56GF) that differ in their F and/or $\mathrm{G}$ protein expression to develop mathematical models to describe and identify the impacts of variations in temperature and $\mathrm{pH}$ on viral clearance and persistence in the environment.

\section{Materials and Methods}

\subsection{Cells and Viruses}

Recombinant RSV strains A2, A2-line19F, A2-91/09GF, and A2-TX11-56GF were produced in Vero cells (ATCC CCL-81) cultured with minimal essential medium (MEM) supplemented with 10 fetal bovine serum (FBS) and a mixture of penicillin, streptomycin, and amphotericin B. Each of these virus strains was engineered to express a red reporter gene, monomeric Katushka 2 (mKate2), and their assembly and initial recoveries using an RSV reverse genetics system have been previously described (Stobart et al. 2016; Hotard et al. 2012). Strains A2-line19F, A2-91/09GF, and A2-TX11-56GF are chimeric viruses that express either the F protein only (from strain Line19) or F and G proteins only (from strain 91/09 or strain TX11-56) in the genetic background of common laboratory strain A2. Generated RSV virus stocks were harvested from Vero cells and flash frozen in liquid nitrogen and stored at $-80^{\circ} \mathrm{C}$ until use.

\subsection{RSV Replication Analysis}

Vero cells at 70-90\% confluency were infected by each of the virus strains at room temperature for $45 \mathrm{~min}$ with a multiplicity of infection (M.O.I) of 0.01. After the initial infection period, the inoculum was removed and the cells washed twice with 1X PBS to remove any residual uninfected virus particles before pre-warmed complete MEM was applied. At specific times post-infection, infected cell monolayers were scraped into the media and flash frozen in a dry ice-isopropanol slurry to be stored at $-80^{\circ} \mathrm{C}$ for titering. Virus titers were determined in Vero cells by quantifying the amount of infected cells as reported by mKate 2 expression after serial dilution as previously described (Stobart et al. 2016). 
The same procedure was repeated for the A2 and A2-line19F strains with an M.O.I of 1 to estimate the length of the eclipse phase, that is, the time from infection to the production of virus.

\subsection{RSV Thermal and pH Inactivation Assays}

Aliquots of each virus were either mixed with $1 \mathrm{X}$ phosphate-buffered saline (PBS) (for thermal inactivation experiments) or with buffered $\mathrm{pH}$ solutions and incubated at either $4{ }^{\circ} \mathrm{C}, 32^{\circ} \mathrm{C}$, or $37^{\circ} \mathrm{C}$. At specific times, a sample was obtained from the incubated virus stocks and flash frozen in a dry ice-isopropanol slurry to be stored at $-80^{\circ} \mathrm{C}$ for titering as described above.

\section{Results}

\subsection{Evaluation of RSV Replication Kinetics}

To generate a model that incorporates both viral replication as well as the roles of temperature and $\mathrm{pH}$ for inactivation, we first performed viral infections in Vero cells to determine the relative kinetics of virus replication and production for four different RSV strains (A2, A2-line19F, A2-91/09GF, and A2-TX11-56GF) that differ in either $\mathrm{F}$ protein expression only (A2-line19F) or in both $\mathrm{F}$ and $\mathrm{G}$ protein expression (A291/09GF and A2-TX11-56GF) (Fig. 1). As reported previously, the viral kinetics of these strains were mostly similar throughout the course of infection with the exception of strain A2-TX11-56GF, that showed delayed replication over the entirety of the 4-day experiment (DeFord et al. 2019).

\subsection{Susceptibility of RSV Strains to Inactivation over Time Under Different Temperatures and pH Conditions}

In order to explore the roles of temperature and $\mathrm{pH}$ on viral clearance, RSV strains A2, A2-line19F, A2-91/09GF, and A2-TX11-56GF were incubated in 3 different temperature conditions $\left(4^{\circ} \mathrm{C}\right.$ [refrigeration temp], $32^{\circ} \mathrm{C}$ [human upper airway temp], and $37^{\circ} \mathrm{C}$ [human core body temp]) or 3 different $\mathrm{pH}$ conditions associated with the airway mucosa $(7.4,6.6$, and 5.8) (Fig. 2). These temperatures and $\mathrm{pH}$ conditions were selected because they either reflect storage temperatures for vaccines or are physiologically relevant for human RSV infections. Over either 4 days (temperature) or 24 hours $(\mathrm{pH})$, aliquots of virus were taken and subsequently titered to determine the amount of virus remaining over time. Consistent with our earlier published studies, all viruses showed decreased viability with longer exposures for both temperature and $\mathrm{pH}$. In addition, exposure to elevated temperatures was associated with faster inactivation with strain A2 showing consistently faster inactivation kinetics (DeFord et al. 2019). Strain-specific differences were observed between the viruses with regards to optimal $\mathrm{pH}$ for stability, however in all cases, strain TX11-56GF appeared to be most sensitive to inactivation. 
Fig. 1 Replication kinetics of recombinant strains of RSV at $37^{\circ} \mathrm{C}$. Vero cells were infected at a ratio of 0.01 infectious virus particles per cell and supernatant was surveyed for virus produced by quantifying fluorescent focus units (f.f.u) per ml. Time points reflect the average virus titer of three experimental replicates with error bars representing 1 standard deviation of the mean

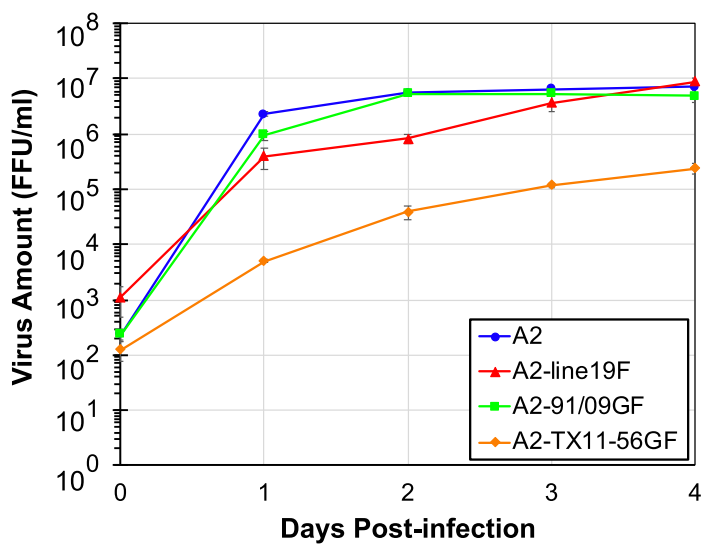

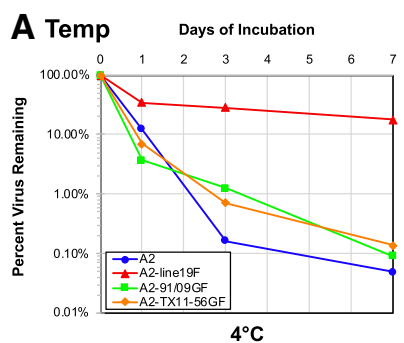
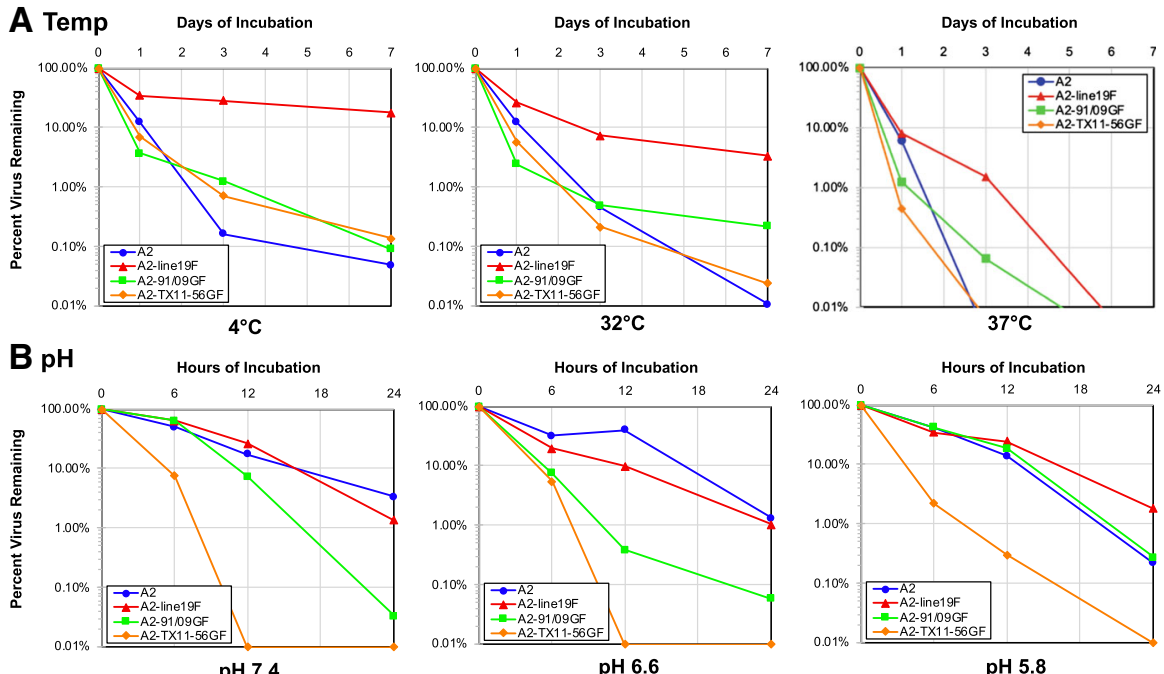

Fig. 2 Susceptibility of RSV strains to inactivation during incubation under different temperatures (A) and $\mathrm{pH}$ conditions (B). RSV strains A2, A2-line19F, A2-91/09GF, and A2-TX11-56GF were incubated in the temperature or $\mathrm{pH}$ conditions incubated and aliquots were acquired at different times $(0-4$ days for temperature or 0-24 hours for $\mathrm{pH}$ ). Harvested virus was subsequently titered on Vero cells to determine the amount of infectious virus remaining post-incubation. Undetectable titers or titers below the limit of detection were reported as $0.01 \%$ percent virus remaining

\subsection{Clearance Model}

Using the thermal and $\mathrm{pH}$ inactivation assays, we constructed a model for viral clearance as a function of temperature and $\mathrm{pH}$ for four different RSV strains: $\mathrm{A} 2$, A2-line19F, A2-91/09GF, A2-TX11-56GF. We also fit a viral kinetics model to the data from the replication analysis at a fixed temperature and $\mathrm{pH}$.

It has been demonstrated that viral clearance varies as a function of temperature and $\mathrm{pH}$ for each of these strains, and we assume that for other parameters associated 
with viral replication (infection and production rates, for example), the dependence on temperature and $\mathrm{pH}$ is negligible. Using the fixed parameters found for the viral kinetics model, we replace the fixed clearance value with the clearance model and generate a viral replication model for each strain as a function of temperature, $\mathrm{pH}$, and time.

The Arrhenius equation gives clearance, $c$, as an exponential function of the reciprocal of temperature, $T_{C}$ :

$$
c=A e^{E_{\mathrm{a}} /\left(k T_{C}\right)},
$$

where $A$ is the maximum clearance, $E_{\mathrm{a}}$ is the activation energy of the reaction, and $k$ is the Boltzmann constant (Bozkurt et al. 2015a, b; Rowell and Dobrovolny 2020).

By the Arrhenius equation, $\log c$ is a linear function of $1 / T_{C}$, and one can see this in the inactivation assays. The percentage of initial titer remaining titer in each inactivation assay was measured at $0,1,3$, and 7 days and decreases exponentially as a function of time. Thus, the remaining titer (on an exponential scale) decreases linearly as a function of time. We used linear regression to find the line that best fit these data and define the clearance to be the absolute value of the slope of the linear regression line for the logarithm of percentage of initial titer as a function of the reciprocal of time.

Experimentally, we found $\log c$ to be a quadratic function of $P$ for $\mathrm{pH}$ values in the interval $[5.6,7.6]$. Similar nonlinear relationships between $c$ and $P$ have been observed in this $\mathrm{pH}$ range in other virus types (Mak et al. 1970). Thus, we construct a model in which $\mathrm{c}$ is an exponential function of both the reciprocal of $T_{C}$ and a quadratic function of $\mathrm{pH}, P$ :

$$
c=\gamma e^{\alpha / T_{C}+\beta_{1} P+\beta_{2} P^{2}}
$$

where $\alpha, \beta_{1}, \beta_{2}$, and $\gamma$ are constants. While these constants have no physical meaning in the model, we can solve for the values of these constants that best model each thermal/pH clearance data set from the four RSV strains. The result will be, for each strain, a real-valued function for $c$, depending on both $T_{C}$ and $P$. These functions can be used to compare differences in clearance behavior between strains as influenced by temperature and $\mathrm{pH}$. For each of the four strains, we have a clearance measurement at each of the following temperature/pH data points, listed as ordered pairs, $\left(T_{C}, P\right)$ :

$$
(4,7.4),(32,7.4),(37,5.8),(37,6.6) \text {, and }(37,7.4)
$$

These can be found in Table 1.

We used multilinear regression on $\ln c$ with these data to identify parameters $\alpha, \beta_{1}$, $\beta_{2}$, and $\ln \gamma$ that produce a model that minimizes the sum of squared residuals (SSR),

$$
\mathrm{SSR}=\sum_{i=1}^{n}\left(y\left(T_{C i}, P_{i}\right)-c\left(T_{C i}, P_{i}\right)\right)^{2},
$$


Table 1 Clearance values from inactivation assays for each strain at each of five temperature and $\mathrm{pH}$ combinations

\begin{tabular}{lccccc}
\hline Temp $\left({ }^{\circ} \mathrm{C}\right)$ & $\mathrm{pH}$ & \multicolumn{5}{l}{ Clearance by strain $\left(R^{2}\right.$-value $)$} \\
\cline { 3 - 6 } & & $\mathrm{A} 2$ & $\mathrm{~A} 2$-line19F & $\mathrm{A} 2-91 / 09 \mathrm{GF}$ & $\mathrm{A} 2$-TX11-56GF \\
\hline \multirow{3}{*}{4} & 2.1043 & 0.2020 & 1.3253 & 1.5772 \\
& 7.4 & $(1)$ & $(0.7295)$ & $(0.8675)$ & $(0.9471)$ \\
32 & & 1.7709 & 0.4441 & 1.6350 & 2.8506 \\
& 7.4 & $(0.9959)$ & $(0.8505)$ & $(0.8379)$ & $(1)$ \\
37 & & 3.9401 & 3.9157 & 3.3763 & 15.2508 \\
& 5.8 & $(0.9966)$ & $(0.9667)$ & $(0.9998)$ & $(1)$ \\
37 & & 4.1585 & 4.4114 & 10.3836 & 11.6711 \\
& 6.6 & $(0.8887)$ & $(0.9851)$ & $(1)$ & $(1)$ \\
37 & & 3.1116 & 1.3595 & 4.6566 & 5.0333 \\
& 7.4 & $(0.9719)$ & $(0.6272)$ & $(0.9569)$ & $(0.9362)$ \\
\hline
\end{tabular}

where $y\left(T_{C i}, P_{i}\right)$ are the values of $c$ from the data set at $\left(T_{C i}, P_{i}\right)$, and $c\left(T_{C i}, P_{i}\right)$ are the values of $c$ predicted by the model.

\subsection{Kinetic Model for RSV Infection}

We fit the viral replication data to a viral kinetics model used in Baccam et al. (2006), González-Parra and Dobrovolny (2018) and Pinilla et al. (2012),

$$
\begin{aligned}
\frac{\mathrm{d} T}{\mathrm{~d} t} & =-\frac{\beta}{N} T V \\
\frac{\mathrm{d} E_{1}}{\mathrm{~d} t} & =\frac{\beta}{N} T V-\frac{n_{E}}{\tau_{E}} E_{1} \\
\frac{\mathrm{d} E_{j}}{\mathrm{~d} t} & =\frac{n_{E}}{\tau_{E}} E_{j-1}-\frac{n_{E}}{\tau_{E}} E_{j} \text { for } j=\left(2, \ldots, n_{E}\right) \\
\frac{\mathrm{d} I_{1}}{\mathrm{~d} t} & =\frac{n_{E}}{\tau_{E}} E_{n_{E}}-\frac{n_{I}}{\tau_{I}} I_{1} \\
\frac{\mathrm{d} I_{j}}{\mathrm{~d} t} & =\frac{n_{E}}{\tau_{I}} I_{j-1}-\frac{n_{I}}{\tau_{I}} I_{j} \quad \text { for } j=\left(2, \ldots, n_{I}\right) \\
\frac{\mathrm{d} V}{\mathrm{~d} t} & =p \sum_{j=1}^{n_{I}} I_{j}-c V .
\end{aligned}
$$

$V$ is the virus population (in f.f.u. $/ \mathrm{mL}$ ) as a function of time $t$ (in days). $T, E$, and $I$ are populations of cells, target, eclipse, and infectious, respectively. Target cells become infected at rate $\beta$ and enter the eclipse phase, in which they are infected by the virus but not yet producing virus. Cells remain in the eclipse phase for an average time, $\tau_{E}$ days. When they begin producing virus at rate $p$, they enter the infectious phase, where they continue to produce virus for an average time, $\tau_{I}$ days, after which they die. Viruses in the system lose infectivity at rate $c$, the virus clearance rate (Fig. 3). 


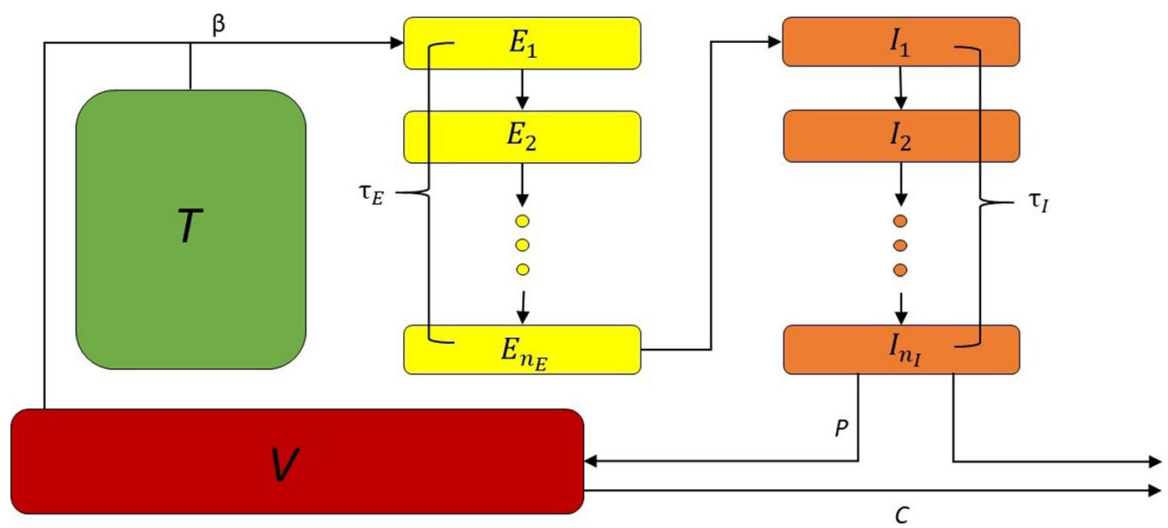

Fig. 3 Kinetics model for RSV replication

The model with $n_{E}=n_{I}=1$ assumes that the durations of $E$ and $I$ both follow an exponential distribution, and this is biologically unrealistic (Holder and Beauchemin 2011). For $n_{I}>30$ or so, the distribution is normal-like and not sensitive to changes in $n_{I}$ (Holder and Beauchemin 2011; Beauchemin et al. 2017).

Identifiability of parameters is a known issue for this model (Miao et al. 2011), but our experimental data give us exact values for some of the typically unknown parameters. Each replication trial was started with $10^{6}$ cells and $10^{4}$ viruses ( 1 virus for each 100 cells). After infection, the remaining viruses were washed away, leaving fewer target cells, a small number of cells in the first eclipse phase, and a very small number of residual virus (free to continue infecting target cells). While the monolayer of cells in the experiment began at 70-90\% confluency, increases in cell replication throughout the experiment were considered negligible due to insufficient surface area for expansion, a doubling rate of approximately $48 \mathrm{~h}$, and reduced replication during active infection.

We define $t=0$ to be the time immediately following the rinsing of the sample, and we assume that $62 \%$ of viruses infected an individual target cell (Follmann et al. 2010; Martin et al. 2020). Thus, we set $T(0)=99.38$ (rescaled by $\left.10^{4}\right), E_{1}(0)=0.62$, $E_{j}(0)=0$ for $2 \leq j \leq n_{E}$, and $I_{j}(0)=0$ for $1 \leq j \leq n_{I}$. We also set $\mathrm{V}(0)$ to be the Day 0 reading from the sample. The replication data were generated at $37^{\circ} \mathrm{C}$ and $\mathrm{pH} 7.4$, so for $c$, we used the clearance value generated from the inactivation assays at that temperature and $\mathrm{pH}$.

We are left to fit parameters $\beta, p, \tau_{E}, \tau_{I}, n_{E}$, and $n_{I}$. As noted in Beauchemin et al. (2017), we found $n_{E} \in[3,7]$ and $n_{I}>6$ to be the most suitable ranges for values of $n_{E}$ and $n_{I}$. All replication assays with an M.O.I of 1 showed virus production beginning well within 24 hours of infection; using these data, we were able to narrow the search range for $\tau_{E}$. We set the following bounds for our parameter search: $\beta \in(0,100)$, $p \in\left(0,10^{16}\right), \tau_{E} \in(0,10), \tau_{I} \in\left(0,10^{3}\right), n_{E} \in[3,7]$, and $n_{I} \in[7,18]$.

Again, parameters were fit to our data set by minimizing SSR,

$$
\mathrm{SSR}=\sum_{i=1}^{n}\left(y\left(t_{i}\right)-V\left(t_{i}\right)\right)^{2},
$$


Table 2 Estimated parameters for the clearance model for each strain

\begin{tabular}{lllll}
\hline & A2 & A2-line19F & A2-91/09GF & A2-TX11-56GF \\
\hline$\gamma$ & $2.2566 \times 10^{-8}$ & $2.67 \times 10^{-24}$ & $2.42 \times 10^{-35}$ & $2.42 \times 10^{-35}$ \\
$\alpha$ & -0.5315 & -6.1698 & -3.3873 & -3.3873 \\
$\beta_{1}$ & 6.0929 & 17.9487 & 25.0091 & 25.0091 \\
$\beta_{2}$ & -0.4859 & -1.4355 & -1.9036 & -1.9036 \\
\hline
\end{tabular}

Table 3 Clearance model error by strain, temperature, and $\mathrm{pH}$

\begin{tabular}{llllll}
\hline$T_{C}$ & $P$ & Error by strain & & \\
\cline { 3 - 6 } & & A2 & A2-line19F & A2-91/09GF & A2-TX11-56GF \\
\hline 4 & 7.4 & -0.0113 & -0.0021 & -0.0129 & -0.0084 \\
32 & 7.4 & 0.5801 & 0.3270 & 1.1184 & 0.9152 \\
37 & 5.8 & $-8.88 \times 10^{-5}$ & 0.0007 & 0.0002 & -0.0004 \\
37 & 6.6 & -0.0001 & 0.0008 & 0.0008 & -0.0004 \\
37 & 7.4 & -0.7553 & -0.5679 & -1.8635 & -1.2034 \\
& SSR & 0.9071 & 0.4295 & 4.7236 & 2.2857 \\
\hline
\end{tabular}

where $y\left(t_{i}\right)$ are the values of $V$ from the data set at times $t_{i}$, and $V\left(t_{i}\right)$ are the values of $V$ predicted by the model with $T_{C}=37, P=7.4$. The SSR was calculated as the parameters $\beta, p, \tau_{E}, \tau_{I}, n_{E}$, and $n_{I}$ varied. Small SSR identifies parameters for which the model error (the difference between model values and actual data values) is small. The fitting was implemented in Mathematica using ParametricNDSolve and FindMinimum functions to minimize SSR with respect to the parameters.

Fixing the best-fitting parameters $\beta, p, \tau_{E}, \tau_{I}, n_{E}$, and $n_{I}$ in the model, we then treat $T_{C}$ and $P$, the variables controlling clearance $c$, as independent variables for $V$, producing virus population $V$ as a function of time $t$, temperature, and $\mathrm{pH}$.

\subsection{Model Fit}

The optimal parameters for the clearance model for each strain can be found in Table 2, and the error at each data point for the models using those parameters are in Table 3. SSR for all strains is low compared to the actual clearance values, indicating that the model error (the difference between model values and actual data values) is also small.

Fixing the parameters from Table 2 for each strain, we have a model for each strain's clearance as a function as a function of temperature and $\mathrm{pH}$. Graphs of these functions can be found in Fig. 4. As noted in DeFord et al. (2019), clearance dependence on temperature and $\mathrm{pH}$ varies a great deal from strain to strain. For $T_{C} \in[0,39]$ and $P \in[5.6,7.6]$, clearance values in the models for A2 and A2-line19F are in a very similar range (never exceeding 6), but vary quite differently with respect to $T_{C}$ and $P$. For example, the A2-line19F model is much more sensitive to change in $P$ than the A 2 model. The A2 model, in general, is comparably stable with respect to both $T_{C}$ and 

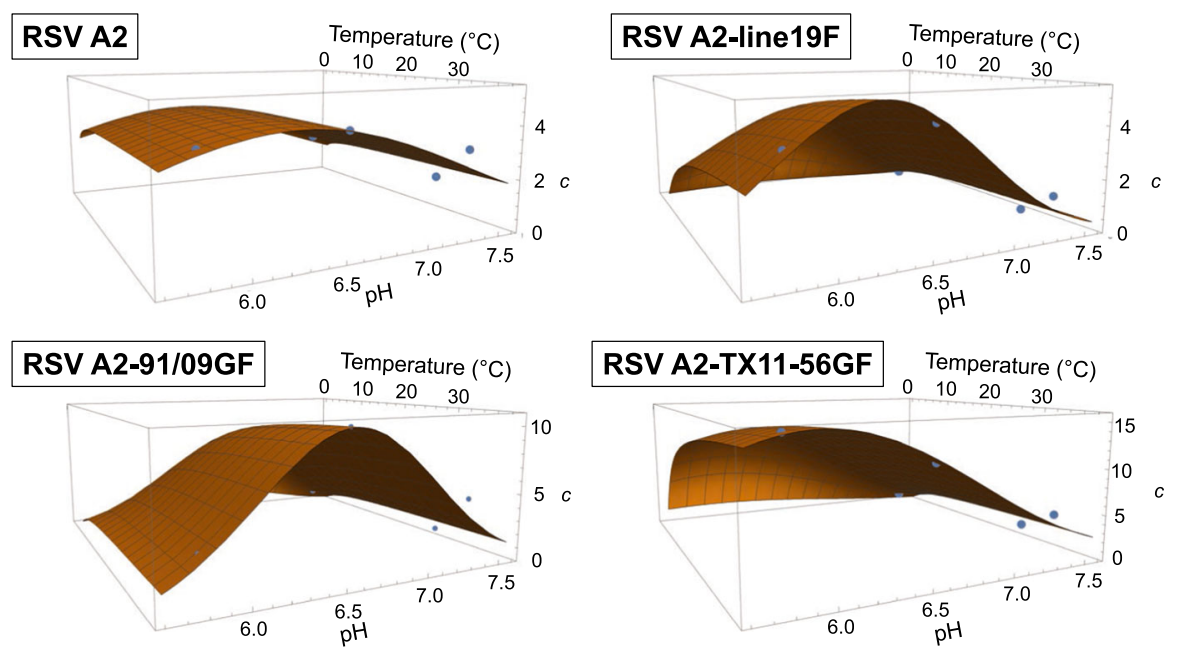

Fig. 4 Clearance, $c$, as a function of Temp and pH. Note, the range for clearance is different for each strain. The blue points indicate actual data from the inactivation assays (Color Figure Online)

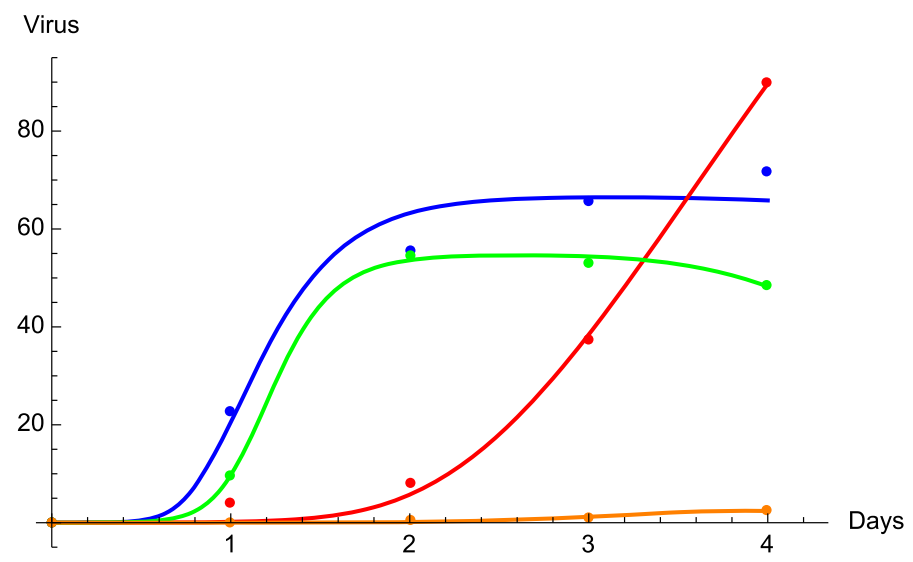

Fig. 5 Kinetic model fit for virus titer $\left(10^{5}\right.$ f.f.u. $\left./ \mathrm{mL}\right)$ as a function of days at Temp 37 and $\mathrm{pH}$ 7.4. Points are data from the replication analysis, and curves are $V(t)$ from the kinetic model using the optimal parameters. A2 is blue, A2-line19F is red, A2-91/09GF is green, and A2-TX11-56GF is orange (Color Figure Online)

$P$. The A2-91/09GF and A2-TX11-56GF models both produce much larger clearance values then either A2 or A2-line19F, A2-TX11-56GF substantially more so. Again, the clearance values vary dramatically with respect to both $T_{C}$ and $P$; in particular, clearance for A2-TX11-56GF remains high for lower values of $P$.

Using the data from the replication analysis taken at $37^{\circ} \mathrm{C}$ and $7.4 \mathrm{pH}$, optimal parameters for the viral kinetics model for each strain (at $37^{\circ} \mathrm{C}$ and $7.4 \mathrm{pH}$ ) are in Table 4. Graphs of virus population with these fixed parameters are plotted with the replication data to which each model was fit (Fig. 5). When comparing to Fig. 1, not that Fig. 1 is on a logarithmic scale, and Fig. 5 is not. 
Table 4 Estimated kinetic model parameters for the four RSV strains

\begin{tabular}{lllll}
\hline & A2 & A2-line19F & A2-91/09GF & A2-TX11-56GF \\
\hline$\beta$ & 11.1872 & 6.5053 & 5.4666 & 5.4492 \\
$p$ & 2.0756 & 2.6373 & 2.5487 & 2.4721 \\
$n_{E}$ & 3 & 3 & 6 & 5 \\
$\tau_{E}$ & 0.4071 & 2.4606 & 0.3729 & 1.526 \\
$n_{I}$ & 8 & 14 & 16 & 9 \\
$\tau_{I}$ & 7.5167 & 3.8487 & 3.9054 & 0.1026 \\
SSR & 9.8968 & 4.7287 & 1.4811 & 0.2361 \\
\hline
\end{tabular}

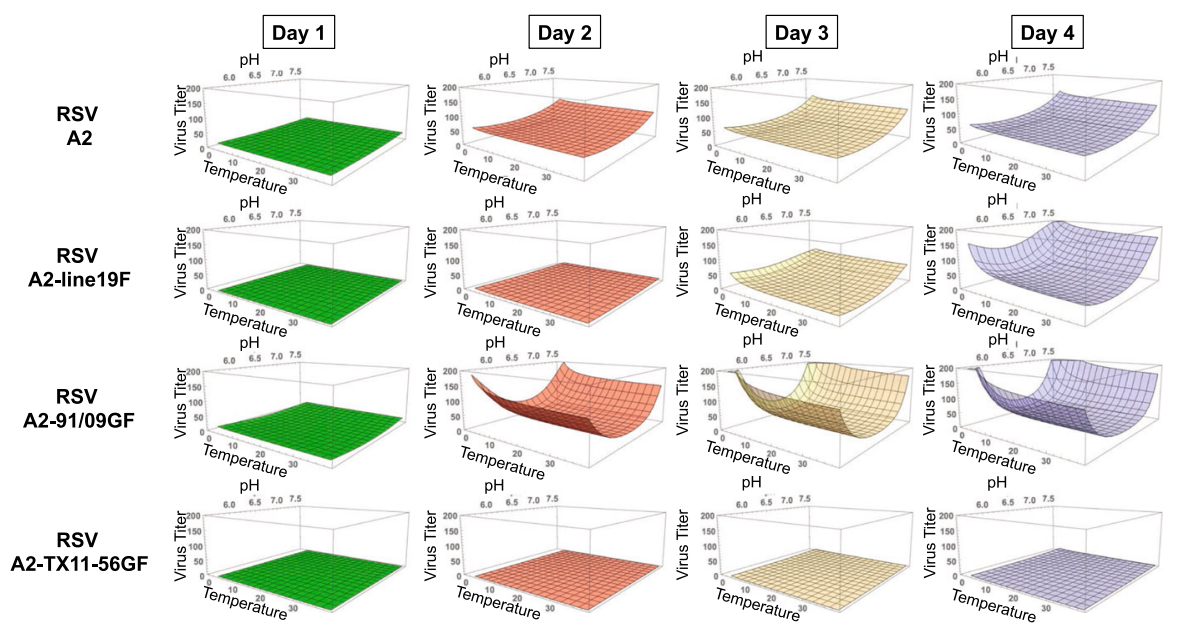

Fig. 6 Virus titer $\left(10^{5}\right.$ f.f.u. $\left./ \mathrm{mL}\right)$ as a function of Temp and $\mathrm{pH}$ for four different times

There is a great deal of difference between strains in the data from the replication analysis taken at $37^{\circ} \mathrm{C}$ and $7.4 \mathrm{pH}$. The virus titer, $V\left(10^{5}\right.$ f.f.u. $\left./ \mathrm{mL}\right)$, for each strain over 4 days is in Fig. 5. The A2 and A2-91/09GF strains exhibit similar growth, quick after the first day before leveling off. A2-line19F and A2-TX11-56GF, on the other hand, both grow slowly initially; while A2-line19F eventually grows quickly, A2TX11-56GF maintains very slow growth. This is the result of the comparably high clearance values for A2-TX11-56GF.

The kinetic model does a good job fitting these data. The optimal parameters and SSR for each strain are in Table 4. Using the optimal parameters, graphs of the model for $V$ (virus titer in $10^{5}$ f.f.u./mL) can also be seen in Fig. 5.

Using the clearance model (with temperature and $\mathrm{pH}$ as independent variables) for clearance in conjunction with the optimal parameters from Table 4 in the kinetic model, we solve for $V$ (virus titer in $10^{5}$ f.f.u. $/ \mathrm{mL}$ ) as a function of $T_{C}, P$, and $t$ (in days) in the kinetic model. We plot graphs of these functions for various fixed $t$ values in Fig. 6. 


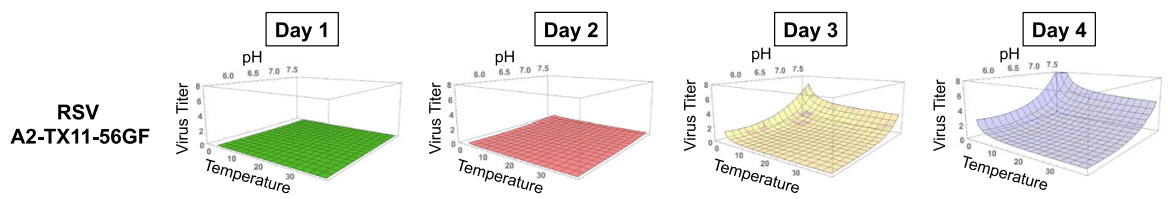

Fig. 7 A closer look at virus titer $\left(10^{5}\right.$ f.f.u./mL) for A2-TX11-56GF as a function of Temp and $\mathrm{pH}$ for four different times

As with the clearance model, growth for A2 in the kinetic model is relatively stable with respect to both $T_{C}$ and $P$. As seen in the data from the replication assays, both A2-line19F and A2-TX11-56GF exhibit very slow growth initially while both A2 and A2-91/09GF grow rapidly from the outset. However, there are still notable differences between strains in how $T_{C}$ and $P$ effect this growth. For both A2-line19F and A291/09GF, growth is considerably faster for low values of $T_{C}$ and extreme values of $P \in[5.6,7.6]$. Growth for A2 is substantially more stable with respect to $T_{C}$ and $P$. For A2-TX11-56GF, however, growth is so slow that it is difficult to see how $T_{C}$ and $P$ actually impact $V$. Fig. 7 shows A2-TX11-56GF with virus titer less than $8 \times 10^{5}$ f.f.u./mL (compared to $200 \times 10^{5}$ f.f.u./mL in Fig. 6). This closer look reveals that growth of A2-TX11-56GF depends on $T_{C}$ and $P$ in a manner that most closely resembles A2-line19F, just much slower; growth for A2-TX11-56GF is considerably faster for low values of $T_{C}$ and high values of $P$ (near 7.6).

These results identify some improvements that could be made on the model for future study. A larger number of data points would improve reliability of the model. We have not included confidence intervals for our parameter estimates in Tables 2 and 4. Estimating four parameters (in the clearance model) and six parameters (in the kinetic model), both with only five data points, made estimates of confidence intervals for these parameters unreliable. Another improvement would be in the clearance model itself; it was shown in Beauchemin et al. (2019) that simple exponential decay is not necessarily the best model for decay of RSV. A more sophisticated model for clearance in future studies would also improve reliability.

\section{Conclusions}

The ecology of viruses in nature is largely dependent upon maintenance of adequate physical stability of virus particles despite the physical and chemical stresses of the viral niche and external environment. For most microbes, including viruses, temperature, and $\mathrm{pH}$ play a critical and important role in defining the host range and environmental conditions required for persistence. In the present study, we used thermal and $\mathrm{pH}$ inactivation data from four different strains (A2, A2-line19F, A2-91/09GF, and A2-TX11-56GF) of respiratory syncytial virus (RSV) were used to develop a model that integrates viral replication with now the roles of temperature and $\mathrm{pH}$ as variables on persistence and clearance during active infection. While other models have been developed in the past to predict viral replication, this is the first RSV model to integrate and explore the roles of temperature and $\mathrm{pH}$ on viral clearance (GonzálezParra and Dobrovolny 2019, 2018). We have previously shown that differences in 
expression of RSV G and F result in differences in viral stability of purified virus (DeFord et al. 2019; Rostad et al. 2018). Consistent with these findings, our present study demonstrates that the variables of time, temperature, and $\mathrm{pH}$ impact these strains differently and suggest that both temperature and $\mathrm{pH}$ may play critical roles in active infections of RSV. During RSV infection, the viral fusion $(F)$ protein undergoes a dynamic conformational change in shape to orchestrate fusion between viral and cellular membranes (McLellan et al. 2013; Krarup et al. 2015). Our data here show that strains A2 and A2-line19F that differ only in the expression of heterologous F proteins result in dramatically different landscapes of persistence (Fig. 6). While our study into the roles of temperature and $\mathrm{pH}$ on virus replication is limited to conditions that maintain cell viability, these data suggest that the amino acid differences in the structures of these proteins may greatly influence the infection dynamics exhibited by these viruses. Furthermore, these data are consistent with infection data both in vitro (in cell culture) as well as in vivo in mouse models (Stobart et al. 2016; Moore et al. 2009). However, perhaps more importantly, this model also suggests that physiologic differences in respiratory mucosa children likely select for certain strains to persist and potentially lead to more pathogenesis.

RSV remains a major cause of both hospitalizations and mortality in young infants and the WHO has identified the need for a vaccine for RSV as a top priority in the next few years (Shi et al. 2017; Giersing et al. 2019). Past efforts to develop an inactivated vaccine for RSV failed miserably and resulted in induction of vaccine-enhanced illness in infants (Kim et al. 1969; Kapikian et al. 1969). Consequently, the primary focus for developing a safe and effective vaccine continues to be on live-attenuated preparations. Live-attenuated vaccines utilize weakened, but actively replicating, forms of pathogens to induce immunity. However, issues related, in part, to the physical stability of RSV have hindered development of both stable and efficacious live-attenuated vaccine candidates. As evidenced by the early storage concerns associated with the COVID-19 mRNA vaccines, vaccine physical stability can have significant impacts on ability to store and deliver vaccines. While this model advances our understanding and predictive capacity of the complex physical and biological dynamics of active RSV infection, there remain several unanswered questions about the biology of RSV infections that continue to limit and introduce uncertainty into RSV models. For instance, previous work from our lab and others has revealed that the dynamic interplay between RSV G protein-mediated attachment and RSV F protein-mediated fusion appears to be both functionally linked and potentially variable between RSV strains (Meng et al. 2015). It has also been demonstrated previously that RSV F is required for virus infectivity, which likely explains the susceptibility to inactivation tied to this protein's expression (Collins and Melero 2011). However, it remains unclear how exactly temperature and $\mathrm{pH}$ variations result in terminal inactivation of viral particles. Having greater understanding of the physical mechanisms of inactivation of RSV may provide new guidance on how to best incorporate external physical pressures into models of RSV infectivity and persistence. Development of vaccine candidates that balance attenuation for safety with persistence and avoidance of clearance in the respiratory epithelium will be critical for future successful vaccine design. The model that we have developed here provides new insight into both the role of variations in viral surface protein expression ( $\mathrm{G}$ and $\mathrm{F}$ ) on the biology of the virus as well as provides a medium to predict how 
future potential live-attenuated vaccine candidates may respond to variations in host environment during post-immunization.

Acknowledgements We would like to thank Darby DeFord and Jenna Nosek for helping establish and collect data related to the assays for virus replication and inactivation. In addition, we would like to thank both the Department of Mathematics, Statistics, and Actuarial Sciences as well as the Department of Biological Sciences at Butler University for their support of this research. This research was also funded by a Holcomb Awards Committee (HAC) grant from Butler University and summer undergraduate research support through the Butler Summer Institute (BSI).

Data Availability Data are available upon request.

\section{Declarations}

Conflict of interest The authors declare that they have no conflict of interest.

Code Availability The model fitting was implemented in Mathematica using ParametricNDSolve and FindMinimum functions; the Mathematica code is available upon request.

\section{References}

Anderson LJ, Hierholzer JC, Stone YO, Tsou C, Fernie BF (1986) Identification of epitopes on respiratory syncytial virus proteins by competitive binding immunoassay. J Clin Microbiol 23(3):475-480. https:// doi.org/10.1128/JCM.23.3.475-480

Baccam P, Beauchemin C, Macken CA, Hayden FG, Perelson AS (2006) Kinetics of influenza A virus infection in humans. J Virol 80(15):7590-7599. https://doi.org/10.1128/JVI.01623-05

Beauchemin CA, Miura T, Iwami S (2017) Duration of shiv production by infected cells is not exponentially distributed: implications for estimates of infection parameters and antiviral efficacy. Sci Rep 7:42765. https://doi.org/10.1038/srep42765

Beauchemin CA, Kim YI, Yu Q, Ciaramella G, DeVincenzo JP (2019) Uncovering critical properties of the human respiratory syncytial virus by combining in vitro assays and in silico analyses. PLoS ONE 14(4):e0214708

Bozkurt H, D'Souza D, Davidson P (2015a) Thermal inactivation kinetics of hepatitis A virus in homogenized clam meat (Mercenaria mercenaria). J Appl Microbiol 119(3):834-844. https://doi.org/10. 1111/jam. 12892

Bozkurt H, D’Souza DH, Davidson PM (2015b) Thermal inactivation kinetics of human norovirus surrogates and hepatitis A virus in Turkey deli meat. Appl Environ Microbiol 81(14):4850-4859. https://doi.org/ 10.1128/AEM.00874-15

Collins PL, Melero JA (2011) Progress in understanding and controlling respiratory syncytial virus: still crazy after all these years. Virus Res 162(1-2):80-99. https://doi.org/10.1016/j.virusres.2011.09.020

DeFord DM, Nosek JM, Castiglia KR, Hasik EF, Franke ME, Nick BC, Abdelnour AM, Haas CE, Junod NA, Latsko KN, Moore ML, Berthrong ST, Rostad CA, Stobart CC (2019) Evaluation of the role of respiratory syncytial virus surface glycoproteins $\mathrm{F}$ and $\mathrm{G}$ on viral stability and replication: implications for future vaccine design. J Gen Virol 100(7):1112-1122. https://doi.org/10.1099/jgv.0.001287

Follmann D, Qin J, Hoshino Y (2010) Estimation of viral infection and replication in cells by using convolution models. J R Stat Soc Ser C (Appl Stat) 59(3):423-435

Giersing BK, Karron RA, Vekemans J, Kaslow DC, Moorthy VS (2019) Meeting report: WHO consultation on Respiratory Syncytial Virus (RSV) vaccine development, Geneva, 25-26 April 2016. Vaccine 37(50):7355-7362. https://doi.org/10.1016/j.vaccine.2017.02.068

González-Parra G, Dobrovolny HM (2018) A quantitative assessment of dynamical differences of RSV infections in vitro and in vivo. Virology 523:129-139. https://doi.org/10.1016/j.virol.2018.07.027 
González-Parra G, Dobrovolny HM (2019) The rate of viral transfer between upper and lower respiratory tracts determines RSV illness duration. J Math Biol 79(2):467-483. https://doi.org/10.1007/s00285019-01364-1

Hall CB, Weinberg GA, Iwane MK, Blumkin AK, Edwards KM, Staat MA et al (2009) The burden of respiratory syncytial virus infection in young children. https://doi.org/10.1056/NEJMoa0804877. Archive Location: world Publisher: Massachusetts Medical Society

Hambling MH (1964) Survival of the respiratory syncytial virus during storage under various conditions. Br J Exp Pathol 45(6):647-655

Holder BP, Beauchemin CA (2011) Exploring the effect of biological delays in kinetic models of influenza within a host or cell culture. BMC Public Health 11(Suppl 1):S10. https://doi.org/10.1186/1471-245811-S1-S10

Hotard AL, Shaikh FY, Lee S, Yan D, Teng MN, Plemper RK, Crowe JE, Moore ML (2012) A stabilized respiratory syncytial virus reverse genetics system amenable to recombination-mediated mutagenesis. Virology 434(1):129-136. https://doi.org/10.1016/j.virol.2012.09.022

Kapikian AZ, Mitchell RH, Chanock RM, Shvedoff RA, Stewart CE (1969) An epidemiologic study of altered clinical reactivity to respiratory syncytial (rs) virus infection in children previously vaccinated with an inactivated rs virus vaccine. Am J Epidemiol 89(4):405-421

Kim HW, Canchola JG, Brandt CD, Pyles G, Chanock RM, Jensen K, Parrott RH (1969) Respiratory syncytial virus disease in infants despite prior administration of antigenic inactivated vaccine. Am J Epidemiol 89(4):422-434. https://doi.org/10.1093/oxfordjournals.aje.a120955

Krarup A, Truan D, Furmanova-Hollenstein P, Bogaert L, Bouchier P, Bisschop IJM, Widjojoatmodjo MN, Zahn R, Schuitemaker H, McLellan JS, Langedijk JPM (2015) A highly stable prefusion RSV F vaccine derived from structural analysis of the fusion mechanism. Nat Commun 6:8143. https://doi. org/10.1038/ncomms9143

Mak TW, O'Callaghan JJ, Colter JS (1970) Studies of the pH inactivation of three variants of Mengo encephalomyelitis virus. Virology 40(3):565-571. https://doi.org/10.1016/0042-6822(70)90200-X

Martin BE, Harris JD, Sun J, Koelle K, Brooke CB (2020) Cellular co-infection can modulate the efficiency of influenza a virus production and shape the interferon response. PLoS Pathog 16(10):e1008974

McLellan JS, Chen M, Leung S, Graepel KW, Du X, Yang Y, Zhou T, Baxa U, Yasuda E, Beaumont T, Kumar A, Modjarrad K, Zheng Z, Zhao M, Xia N, Kwong PD, Graham BS (2013) Structure of RSV fusion glycoprotein trimer bound to a prefusion-specific neutralizing antibody. Science (New York, NY) 340(6136):1113-1117. https://doi.org/10.1126/science.1234914

Meng J, Stobart CC, Hotard AL, Moore ML (2014) An overview of respiratory syncytial virus. PLoS Pathog. https://doi.org/10.1371/journal.ppat.1004016

Meng J, Hotard AL, Currier MG, Lee S, Stobart CC, Moore ML (2015) Respiratory syncytial virus attachment glycoprotein contribution to infection depends on the specific fusion protein. J Virol 90(1):245-253

Miao H, Xia X, Perelson AS, Wu H (2011) On identifiability of nonlinear ODE models and applications in viral dynamics. SIAM Rev 53(1):3-39. https://doi.org/10.1137/090757009

Moore ML, Chi MH, Luongo C, Lukacs NW, Polosukhin VV, Huckabee MM, Newcomb DC, Buchholz UJ, Crowe JE, Goleniewska K, Williams JV, Collins PL, Peebles RS (2009) A chimeric A2 strain of respiratory syncytial virus (RSV) with the fusion protein of RSV strain line 19 exhibits enhanced viral load, mucus, and airway dysfunction. J Virol 83(9):4185-4194. https://doi.org/10.1128/JVI.0185308

Munir S, Hillyer P, Le Nouën C, Buchholz UJ, Rabin RL, Collins PL, Bukreyev A (2011) Respiratory syncytial virus interferon antagonist NS1 protein suppresses and skews the human T lymphocyte response. PLoS Pathog 7(4):e1001336. https://doi.org/10.1371/journal.ppat.1001336

Nguyen VK, Binder SC, Boianelli A, Meyer-Hermann M, Hernandez-Vargas EA (2015) Ebola virus infection modeling and identifiability problems. Front Microbiol. https://doi.org/10.3389/fmicb.2015. 00257

Perelson AS, Neumann AU, Markowitz M, Leonard JM, Ho DD (1996) HIV-1 dynamics in vivo: virion clearance rate, infected cell life-span, and viral generation time. Science 271(5255):1582-1586. https:// doi.org/10.1126/science.271.5255.1582

Pinilla LT, Holder BP, Abed Y, Boivin G, Beauchemin CA (2012) The h275y neuraminidase mutation of the pandemic $\mathrm{a} / \mathrm{h} 1 \mathrm{n} 1$ influenza virus lengthens the eclipse phase and reduces viral output of infected cells, potentially compromising fitness in ferrets. J Virol 86(19):10651-10660 
Rostad CA, Stobart CC, Todd SO, Molina SA, Lee S, Blanco JCG, Moore ML (2018) Enhancing the thermostability and immunogenicity of a respiratory syncytial virus (RSV) live-attenuated vaccine by incorporating unique RSV Line19F protein residues. J Virol. https://doi.org/10.1128/JVI.01568-17

Rowell CER, Dobrovolny HM (2020) Energy requirements for loss of viral infectivity. Food Environ Virol 12(4):281-294. https://doi.org/10.1007/s12560-020-09439-9

Shi T, McAllister DA, O’Brien KL, Simoes EAF, Madhi SA, Gessner BD et al (2017) Global, regional, and national disease burden estimates of acute lower respiratory infections due to respiratory syncytial virus in young children in 2015: a systematic review and modelling study. The Lancet 390(10098):946-958. https://doi.org/10.1016/S0140-6736(17)30938-8

Simões EAF, Bont L, Manzoni P, Fauroux B, Paes B, Figueras-Aloy J, Checchia PA, Carbonell-Estrany $\mathrm{X}$ (2018) Past, present and future approaches to the prevention and treatment of respiratory syncytial virus infection in children. Infect Dis Ther 7(1):87-120. https://doi.org/10.1007/s40121-018-0188-Z

Stobart CC, Rostad CA, Ke Z, Dillard RS, Hampton CM, Strauss JD, Yi H, Hotard AL, Meng J, Pickles RJ, Sakamoto K, Lee S, Currier MG, Moin SM, Graham BS, Boukhvalova MS, Gilbert BE, Blanco JCG, Piedra PA, Wright ER, Moore ML (2016) A live RSV vaccine with engineered thermostability is immunogenic in cotton rats despite high attenuation. Nat Commun 7:13916. https://doi.org/10.1038/ ncomms 13916

Thornhill EM, Verhoeven D (2020) Respiratory syncytial virus's non-structural proteins: masters of interference. Front Cell Infect Microbiol. https://doi.org/10.3389/fcimb.2020.00225

Wright PF, Karron RA, Belshe RB, Shi JR, Randolph VB, Collins PL, O’Shea AF, Gruber WC, Murphy BR (2007) The absence of enhanced disease with wild-type respiratory syncytial virus infection occurring after receipt of live, attenuated. Respiratory syncytial virus vaccines. Vaccine 25(42):7372-7378. https://doi.org/10.1016/j.vaccine.2007.08.014

Publisher's Note Springer Nature remains neutral with regard to jurisdictional claims in published maps and institutional affiliations. 